\title{
Depressive symptoms after a sexual assault among women: understanding victim-perpetrator relationships and the role of social perceptions
}

\author{
N Abrahams', R Jewkes², S Mathews' \\ ${ }^{1}$ Gender \& Health Research Unit, Medical Research Council, Tygerberg, Cape Town, South Africa \\ Gender \& Health Research Unit, Medical Research Council, Pretoria, South Africa
}

\begin{abstract}
Objective: Although mental health impact of gender based violence has been documented for many decades, the impact of the socio-cultural dimensions and type of perpetrator on mental health outcomes has not been described outside of developed countries. We explore depression symptomatology four to six weeks post-rape in South Africa and examine whether this differs according to the circumstances of the rape. Method: 140 participants recruited from public hospital services in the Eastern and Western Cape provinces were interviewed within two weeks after completing the post exposure prophylaxis (PEP) medication. A structured questionnaire was used to collect data on socio-demographic and sexual assault characteristics including perpetrator. Depressive symptomatology was measured using the Centre for Epidemiological Studies Depression Scale. Results: 84.3\% (95\% CI: 78.1-90.3) women were found to have high levels of depressive symptoms, but lower levels were found among women raped in circumstances in which there was a lesser likelihood of blame such as those raped by strangers rather than intimate partners (Odds Ratio: (OR) 0.28 (95\% Confidence Intervals (CI): 0.11-0.69) and higher levels were associated with experiencing four or more side effects related to PEP medication (OR: 3.79: CI: 1.03-13.94). Receiving support and severe sexual assaults (involving weapons and multiple perpetrators) were not associated with depression. Conclusion: The study does not support the general assumption that more violent rape causes more psychological harm. These results have important implications for individual treatment because it is more generally assumed that multiple perpetrator rapes, stranger rapes and those with weapons would result in more psychological trauma and thus more enduring symptoms. Our findings point to the importance of understanding the socio-cultural dimensions, including dynamics of blame and stigma, of rape on mental health sequelae.
\end{abstract}

Keywords: Sexual assault; Depression; Rape; Victim-perpetrator relationship

Received: 31-08-2012

Accepted: $31-10--2012$

doi: http://dx.doi.org/10.4314/ajpsy.v16i4.39

\section{Introduction}

Sexual assault can be psychologically devastating for survivors and this aspect of impact is often not addressed in post-rape care. After rape, survivors often develop a cluster of symptoms of posttraumatic stress disorder (PTSD) and may develop depression, obsessive-compulsive disorders, panic attacks, substance abuse and suicidal ideation. ${ }^{1-5}$ Survivors show considerable individual variation in symptom patterns, intensity and duration after rape

\section{Correspondence}

Ms N Abrahams

Gender \& Health Research Unit, Medical Research Council

P O Box 19070, Tygerberg, 7405, Cape Town, South Africa

email: nabraham@mrc.ac.za and it has been suggested that the circumstances of the rape may influence mental health impact.

Early studies form the US show how negative social reactions following a sexual assault increase psychological symptoms. These negative reactions and judgments from others largely follow myths about where it took place, severity of the attack, and pre- attack behaviours (alcohol intake), which all may lead to selfblame. ${ }^{7}$ Although some form of self-blame is common across different traumas, the recent study from Moor and Farchi ${ }^{8}$ has shown how rape victims have considerable higher levels of selfblame compared to other trauma groups and this has important implications for treatment and support.

Sexual violence research findings on victim offender relationships and mental health are mixed ${ }^{9-11}$ and no studies have 
been reported from low and middle income settings.

Comparisons between studies are difficult because of differences in how perpetrators are defined and mental health indicators used, with self-blame a common measure used because it is known as a sequel to sexual violence. Temple ${ }^{11}$ reported that assault by a current partner was strongly predictive of PTSD, stress and disassociation while non-partner sexual assault was only associated with PTSD for African American women (and not for Euro-American and Mexican American Women). In a study of more than 1000 women Ullman ${ }^{10}$ also found negative social reactions predictive of PTSD across all types of offenders. In a small set of survivors Miller ${ }^{12}$ found less self-blame if the perpetrator was known, suggesting that women blame themselves for getting into situations of danger with strangers. There are also mixed results from a review of social support after rape. Ullman ${ }^{13}$ showed that support can have both positive and negative impacts on the recovery process. People who initially withdrew from society after disclosure coped better in the long term, suggesting that these survivors were less exposed to negative and harmful reactions and therefore protected themselves. ${ }^{13}$

Rape stigma is also important. No other group of trauma victims are blamed for their situation as much as rape victims. ${ }^{8}$ Societies generally have myths about rape that are remarkably consistent across diverse areas of the globe. Generally certain types of sexual assault such as by strangers are more likely to be viewed as a crime ("real rape"), whereas others are viewed quite differently, especially intimate partner rape or non-partner rape in certain circumstances (such as rape in a tavern). ${ }^{14}$ Because rape myths are widely held they have a direct impact on the responses from people close to a rape survivor, including family, friends and service providers. It seems reasonable to expect that perceptions of legitimacy and support after rape would influence

psychological reactions.

In this study we explore depressive symptoms four to six weeks post-rape and explore whether this differs according to the circumstances of the rape. The data were generated in an intervention study that tested a telephonic psycho-social support intervention to improve adherence to post exposure prophylaxis to prevent HIV following a sexual assault. The findings of this study have been reported elsewhere..$^{15}$

\section{Method}

\section{Site/s}

Participants were recruited at public sexual assault health centers in the Eastern and Western Cape provinces between August 2007 and May 2008. These were the Sinawe Sexual Assault Service Centre in Mthatha and in Cape Town the sites were the Karl Bremer Hospital, the Simelela Centre in Khayelitsha (all three centres now Thuthuzela centres) and Victoria Hospital. Rape survivors attending the Mthatha service were from the town of Mthatha and its rural hinterland while those attending the Cape Town services were from mainly from urban communities.

\section{Participants}

The participants ( $\mathrm{n}=140)$ were HIV negative adults and adolescents (over age 16) recruited into an intervention study to improve adherence to post exposure prophylaxis for HIV after a sexual assault. Eligibility requirements for the initial study included a negative HIV test, acceptance of the PEP medication and having their own cell phone. In addition we did not approach or seek consent from participants who were emotional distressed such as very tearful or who appeared very anxious at the time of the recruitment at the rape centres. Rape in the current study was defined as vaginal and anal penetration, since the focus of the main study was prevention of HIV after rape. Among the participants, 67 (47.9\%) received the main intervention which consisted of telephonic support by a trained counsellor.

\section{Data}

Face to face interviews were conducted within one to two weeks of completing the PEP medication which is between four to six weeks after the sexual assault. A structured questionnaire was used that included items on socio-demographic characteristics, information related to the sexual assault, the PEP medication, assistance and support (from family and friends - excluding assistance from services) received and experiences of side effects of the drugs. The latter was measured by asking participants if they ever experienced headaches, nausea, vomiting, diarrhoea, rashes, pimples constipation, tiredness or any other side effects during the time of taking the PEP drugs. Variables on the rape included relationship to the perpetrator, number of perpetrators, use of a weapon during attack and contact with the perpetrator after the rape. Depressive symptomatology was measured using the Centre for Epidemiological Studies Depression Scale (CES-D scale)..$^{16}$ This scale has been used extensively and validated in South Africa. 17-19 Twenty questions were asked and reflected on the feelings, emotions and experiences within the last week as well as their frequency. The score range between 0 and 60 with higher scores indicating more symptoms. For this study a score of 16 and more was considered as indicative of high levels of depressive symptomatology, a cut-off used in many other South African studies. ${ }^{17,19} \mathrm{We}$ also tested a score of 22 or more (i.e. very high levels) in a 2nd logistic regression model.

\section{Data analysis}

STATA 12.0 statistical software was used to analyse the data (20). We dichotomised the depression scores with two cut points: $(0=<16$ and $1=16+)$ and $(0=<22$ and $1=22+)$ and present frequency and percentages, with the differences between the groups tested using Pearson's chi-square test. Odds ratios were used to measure associations between depressive symptoms and selected variables. We used logistic regression to model factors associated with depressive symptoms (at the two cut points), with each model controlled for age, race/study site and intervention group. We combined the race and study site variable since all participants from the Mthatha site were African and recoded the variable into four groups: Mthatha:African, Cape Town:African, Cape Town:Colored and Cape Town:White. We combined two variables multiple perpetrators and weapon use into a new dichotomous variable "severe violence". Rape was said to involve 'severe violence' if there were multiple perpetrators or weapon use. We also dicotomised the side effects by frequency reported $(0=<4$ side effects $1=4+$ side effects $)$.

\section{Ethics}

Ethical Approval for the study was granted by the Medical Research Council. Participants were assessed for eligibility and written consent was only initiated after they received standard post-rape care. 


\section{Results}

The overall study had a response rate of $92.3 \%$. Just more than a quarter of the participants (27.9\%) were from the Eastern Cape. The median age of the women was 21 and the majority had ten or more years of education while a third was employed. Although more than half of the women knew the perpetrator (59.3\%), only one in six of the perpetrators were an intimate partner (16.7\%). Nearly half of the women (42.9\%) were raped by multiple perpetrators. $84.3 \%$ (95\% CI: 78.1-90.3) of the women had a depression symptom score of 16 or over. There was no significant difference in depressive scores between those that were in the intervention arm compared to those in the control arm ( $p=0.61)$ but there was a significant difference between the study sites with lower levels of depression found for Mthatha women (56.1\%) compared to the Cape Town based women (83.2\%) $(p=0.001)$.

Table I presents the unadjusted associations between depression symptomatology and demographic and sexual assault characteristics. The highest level of education, being

Table I: Proportions and unadjusted associations between depression symptomatology (scored CES-D 16+) and demographic, sexual assault and taking of PEP medication characteristics

\begin{tabular}{|c|c|c|c|}
\hline & $\begin{array}{l}\text { Depressed } \\
n=118 \\
n(\%)\end{array}$ & $\begin{array}{l}\text { Not Depressed } \\
n=22 \\
n(\%)\end{array}$ & $\begin{array}{l}\text { Odds Ratio } \\
\text { (95\% Cl) }\end{array}$ \\
\hline Mean age (SD) $P$ value & $22.6(7.02)$ & $24.6(8.26)$ & 0.85 \\
\hline $\begin{array}{l}\text { Education (years completed) } \\
<8 \\
8-9 \\
10-11 \\
>11\end{array}$ & $\begin{array}{l}10(8.6) \\
20(16.9) \\
67(56.8) \\
21(17.8)\end{array}$ & $\begin{array}{l}2(9.1) \\
3(13.6) \\
13(59.1) \\
4(18.2)\end{array}$ & $\begin{array}{l}\text { Ref } \\
1.33(0.19-9.31) \\
0.97(0.20-5.26) \\
1.05(1.09-22.81)\end{array}$ \\
\hline $\begin{array}{l}\text { Race \& Study site } \\
\text { African: Mthatha site } \\
\text { African: Cape Town site } \\
\text { Colored: Cape Town site } \\
\text { White: Cape Town site }\end{array}$ & $\begin{array}{l}28(23.1) \\
34(28.8) \\
51(43.2) \\
5(4.2)\end{array}$ & $\begin{array}{l}10(45.5) \\
10(45.5) \\
1(4.5) \\
1(4.5)\end{array}$ & $\begin{array}{l}\text { Ref } \\
1.21(0.44-3.33) \\
18.21(2.21-149.7) \\
1.78(0.18-17.20)\end{array}$ \\
\hline $\begin{array}{l}\text { Employment } \\
\text { Student } \\
\text { Employed } \\
\text { Unemployed }\end{array}$ & $\begin{array}{l}31(26.3) \\
40(33.9) \\
47(39.8)\end{array}$ & $\begin{array}{l}10(45.5) \\
8(36.4) \\
4(18.2)\end{array}$ & $\begin{array}{l}\text { Ref } \\
1.6(0.56-4.56) \\
3.79(1.09-13.16)\end{array}$ \\
\hline $\begin{array}{l}\text { Intervention Group } \\
\text { No } \\
\text { Yes }\end{array}$ & $\begin{array}{l}61(51.7) \\
57(48.3)\end{array}$ & $\begin{array}{l}12(54.5) \\
10(45.5)\end{array}$ & $\begin{array}{l}\text { Ref } \\
1.12(0.44-2.79)\end{array}$ \\
\hline $\begin{array}{l}\text { The perpetrator was a stranger } \\
\text { No } \\
\text { Yes }\end{array}$ & $\begin{array}{l}74(62.7) \\
44(37.3)\end{array}$ & $\begin{array}{l}7(31.8) \\
15(68.2)\end{array}$ & $\begin{array}{l}\text { Ref } \\
0.27(0.10-0.73)\end{array}$ \\
\hline $\begin{array}{l}\text { More than one perpetrators } \\
\text { No } \\
\text { Yes }\end{array}$ & $\begin{array}{l}70(60.3) \\
46(39.7)\end{array}$ & $\begin{array}{l}5(26.3) \\
14(73.7)\end{array}$ & $\begin{array}{l}\text { Ref } \\
0.23(0.07-0.69)\end{array}$ \\
\hline $\begin{array}{l}\text { Weapon was used in attack } \\
\text { No } \\
\text { Yes }\end{array}$ & $\begin{array}{l}53(46.1) \\
62(53.9)\end{array}$ & $\begin{array}{l}5(25.0) \\
15(75.0)\end{array}$ & $\begin{array}{l}\text { Ref } \\
0.38(0.13-1.14)\end{array}$ \\
\hline $\begin{array}{l}\text { Severe violence experienced (weapon \& multiple perpetrators)* } \\
\text { No } \\
\text { Yes }\end{array}$ & $\begin{array}{l}37(31.9) \\
79(68.1)\end{array}$ & $\begin{array}{l}1(5.0) \\
19(95.0)\end{array}$ & $\begin{array}{l}\text { Ref } \\
0.11(0.01-0.87)\end{array}$ \\
\hline $\begin{array}{l}\text { Received assistance and support from family and friends } \\
\text { No } \\
\text { Yes }\end{array}$ & $\begin{array}{l}66(55.9) \\
52(44.1)\end{array}$ & $\begin{array}{l}7(31.8) \\
15(68.2)\end{array}$ & $\begin{array}{l}\text { Ref } \\
0.36(0.13-0.96)\end{array}$ \\
\hline $\begin{array}{l}\text { Experienced } 4 \text { or more side effects } \\
\text { No } \\
\text { Yes }\end{array}$ & $\begin{array}{l}87(73.7) \\
31(26.3)\end{array}$ & $\begin{array}{l}19(86.4) \\
3(13.6)\end{array}$ & $\begin{array}{l}\text { Ref } \\
2.25(.62-8.15)\end{array}$ \\
\hline $\begin{array}{l}\text { Adhere to PEP } \\
\text { No } \\
\text { Yes }\end{array}$ & $\begin{array}{l}70(59.3) \\
48(40.7)\end{array}$ & $\begin{array}{l}11(50.0) \\
11(50.0)\end{array}$ & $\begin{array}{l}\text { Ref } \\
0.68(0.27-1.70)\end{array}$ \\
\hline
\end{tabular}


Table II: Logistic regression models of associations with depression symptomatology (CESD cut points 16+ and 22+), with terms included for age, intervention group race and site

\begin{tabular}{|c|c|c|c|c|}
\hline & Depression: CES-D S & & Depression: CES-D & \\
\hline Age & $1.01(.94-1.09)$ & 0.62 & $1.04(0.98-1.11)$ & 0.15 \\
\hline $\begin{array}{l}\text { Intervention group } \\
\text { Yes } \\
\text { No }\end{array}$ & $1.17(0.43-3.22)$ & 0.74 & $\begin{array}{l}\text { Ref } \\
1.45(0.60-3.50)\end{array}$ & 0.40 \\
\hline $\begin{array}{l}\text { Race \& Study Site } \\
\text { African: Mthatha site } \\
\text { African: Cape Town site } \\
\text { Coloured: Cape Town site } \\
\text { White: Cape Town site }\end{array}$ & $\begin{array}{l}\text { Ref } \\
1.23(0.42-3.57) \\
17.27(2.03-146.96) \\
1.90(.18-19.88)\end{array}$ & $\begin{array}{l}0.69 \\
0.00 \\
0.59\end{array}$ & $\begin{array}{l}\text { Ref } \\
3.12(1.11-8.73) \\
11.16(3.30-37.76) \\
.97(.15-6.23)\end{array}$ & $\begin{array}{l}0.03 \\
0.00 \\
0.97\end{array}$ \\
\hline $\begin{array}{l}\text { Experienced Side Effects } \\
<4 \text { side effects } \\
4+\text { side effects }\end{array}$ & & & $\begin{array}{l}\text { Ref } \\
3.79(1.03-13.94)\end{array}$ & 0.04 \\
\hline $\begin{array}{l}\text { Perpetrator status } \\
\text { Not a stranger } \\
\text { Stranger }\end{array}$ & $\begin{array}{l}\text { Ref } \\
0.28(0.10-0.79)\end{array}$ & 0.01 & $\begin{array}{l}\text { Ref } \\
0.28(0.11-0.69)\end{array}$ & 0.00 \\
\hline
\end{tabular}

Coloured and unemployed were associated with a greater likelihood of depression while a lesser likelihood of depression was associated with rape by a stranger, rape by multiple perpetrators, more severe violence, and receiving assistance from various groups of people.

Two logistic regression models were built to describe the associations between two different cut-offs of depression symptomology score and rape experiences controlling for age, race and participation in intervention (Table II). Women whose perpetrator was a stranger had a lower likelihood of depression symptoms in both models. Those experiencing more than 4 side effects had a greater likelihood of very high levels of depression symptomatology (score < 22). There was a greater likelihood of reporting very high levels of depression symptoms among Colored and African women from Cape Town compared to African women from the Mthatha site for the higher score. The same pattern was seen just for Coloured women when moderately elevated symptoms were examined. Further analysis by race showed significant differences in rape related factors between sites and racial groups. The majority of rape with weapons and multiple perpetrator rape was experienced by African women, especially those from Mthatha. African women were less likely to report experience of side effects of the medication and more likely to receive support from others (Table III).

\section{Discussion}

The data confirms the significant mental health burden of sexual violence and suggests that emotional sequelae were largely dependent on the socio-cultural context of the rape. The lower likelihood of depressive symptoms among the victims assaulted by strangers compared to known perpetrators is most likely explained by the attribution of responsibility and blame, as well as possibly a sense of betrayal and broken trust by intimate partners

\begin{tabular}{|l|l|l|l|l|l|}
\hline \multicolumn{2}{|l|}{ Table III: Frequency of rape related experiences by race and site } & $\begin{array}{l}\text { African } \\
\text { Mthatha } \\
n=38\end{array}$ & $\begin{array}{l}\text { African } \\
\text { Cape Town } \\
n=44\end{array}$ & $\begin{array}{l}\text { Coloured } \\
\text { Cape Town } \\
n=51\end{array}$ & Pvalue \\
\hline Weapon involved & $75(58.6)$ & $28(80.0)$ & $27(62.8)$ & $20(40.0)$ & 0.00 \\
\hline Multiple perpetrator & $59(45.7)$ & $31(86.1)$ & $24(54.6)$ & $4(8.2)$ & 0.00 \\
\hline Stranger rape & $56(42.1)$ & $17(44.4)$ & $20(45.5)$ & $19(37.3)$ & 0.66 \\
\hline Side effects experienced & $31(23.5)$ & $2(5.3)$ & $13(30.2)$ & $16(31.4)$ & 0.00 \\
\hline Received support & $66(49.6)$ & $23(60.5)$ & $26(59.1)$ & $17(33.3)$ & 0.01 \\
\hline
\end{tabular}


or people known to the survivor. A further explanation for our findings of less depression among stranger rapes could be linked to survivors of stranger rapes experiencing less secondary victimisation and receiving more empathy and support and less blame which assist with coping and healing in the period following the rape. Social and cultural norms on sexual activities within relationships often means that when women disclose rapes by known perpetrators (intimate partners or acquaintances) they are often not believed, blamed for their own situation or shamed by families and support services (health, justice, police and even social services).This is supported by the findings at the unadjusted level where rapes which were more aggressive such as those involving weapons and multiple perpetrators were the rapes where victims were less likely to experience depression. This finding seems to point to the importance of social reactions and how rape is defined and perceived as a violent crime.

Only limited comparisons can be made with other studies because of how severe assaults are measured and the absence of the measurement of mental health outcomes after a rape. However a US based study ${ }^{14}$ compared physical trauma and severity between stranger and non-stranger rapes and found similar associations as our study with stranger rapes more likely to be associated with the use of weapons. In another study weapons were found to be predictive of distress. ${ }^{21}$ Women experiencing such rapes are also more likely to blame themselves and therefore do not receive the support they need. Sexual violence by strangers also does not impact on issues of trust as much as for known perpetrators, and the attack is usually a once off event and does not occur with other forms of IPV which may influence the mental health impact. This supports the hypothesis that the role of the social context in which rapes happens impacts on post traumatic self-blame and coping. The racial stratified analysis in our study supports this, and may explain the greater likelihood of depression among Coloured participants compared to African women. Other factors such as health service experiences might also possibly explain the racial differences but it is unlikely because of the lack of difference found between Africans from Cape Town and those from Mthatha. Other factors such as previous experiences of violence could also explain the differences but these were not explored in our study. However it is possible that Coloured women have higher levels of depression before the sexual assault. The South African Stress and Health survey found mood disorders (include depressive disorders) the second leading lifetime psychiatric disorder in the national study ${ }^{22}$ and women was more likely to experience lifetime and 12 month major depression compared to men. ${ }^{23}$ The national survey does not provide analysis stratified by race and sex. However household surveys have shown the Western Cape Province having the highest levels of alcohol use and risky alcohol drinking compared to other provinces ${ }^{24-}$ ${ }^{26}$ and the high demand and allocation of resources for alcohol and substance abuse services in the province recently ${ }^{27}$ are all indicative of the higher mental health morbidity in this province. We were not able to control for pre-rape mental health morbidity, but this should not have affected the association between aspects of the rape and depression symptoms in Coloured women either.

In a recent review of mental health impact following sexual assault Campbell28 presents a revised ecological theoretical model for understanding how social factors interact at multiple levels on the mental health of survivors and self- blame is recognized as a critical factor that evolves from all the levels. Miller et al ${ }^{12}$ suggest it is the difference in post- traumatic self-blame that is important in the treatment of rape victims and that interventions such Cognitive Behavior Therapy (CBT) and others focus on trauma overall while rape victims have additional distress which must be recognized and addressed. We were not able to measure self-blame, PTSD or positive and negative social reactions directly but we did collect data on support sought and provided and these were not found to be associated with depression at the multivariate level.

The increased likelihood for depression when four or more side effects experienced were for the lower depression cut of is not surprising - given the unpleasantness of the drugs that survivors have to take but it may also be depressed women are more sensitized to side-effects. During qualitative research it was shown how survivors struggle taking the medication, predominantly during the lst week when the pill burden is highest with the addition of drugs for infection and pregnancy prevention. Experiencing the physical side effects of the drugs brought about intrusive visions of their own possible HIV illness, leading to distress and anguish. ${ }^{15}$

Our study has limitations as firstly we only measured depression within 5-6 weeks following the sexual assault and the instrument measured their feelings and emotions within the last week. Although all of the participants tested HIV negative at time of enrollment, and the adherence to the PEP drugs was not associated with depression, qualitative research has shown how emotional challenging and difficult it is to adhere to these drugs and rape and HIV stigma played important roles in women's ability to adhere. ${ }^{29}$ No previous studies have considered HIV as a factor that might contribute to mental health impact. This analysis was based on a study that explored adherence to post exposure prophylaxis so many theoretical important variables were not included such as prior victimisation, alcohol and drug use, the recovery process, support systems, coping strategies including blame and selfblame, and other mental health outcomes such as PTSD. Also the study sample was from a group or women who sought help and not representative of all women in population that experience sexual assault. The very high levels of multiple perpetrator rape and weapon use among African women is likely a reflection of reporting bias, as there is a disproportional likelihood of such rape being reported to the police, but would not affect the relationship between these aspects of rape and depression. Our measure of support was limited as we did not look at how extensively women sought support and whether it was helpful at all. Despite these limitations the study provide important evidence of the impact of sexual violence on depression symptoms four weeks after rape and the differential impact by type of perpetrator. 


\section{Conclusion}

The study showed that there were fewer depressive symptoms among women raped in circumstances in which there was a lesser likelihood of blame. These were the rapes where perpetrators were strangers. These results have important implications for individual treatment because it is more generally assumed that multiple perpetrator rapes, stranger rapes and those with weapons would result and more psychological trauma and thus more enduring symptoms. Our findings point to the importance of understanding the socio-cultural aspects of rape in mental health sequelae. The study complements literature on the importance of mental health support in PEP drug adherence and highlights the need for broad based interventions in the general population. Specifically, to challenge rape myths and reduce rape stigma, particularly in a country like South Africa where rape is highly prevalent.

\section{Acknowledgements}

Funding support for the study was provided by Irish Aid and from baseline Medical Research Council Funds. The funders had no role in study design, data collection and analysis, decision to publish, or preparation of the manuscript.

\section{References}

1. Kilpatrick DG, Veronen LJ, Resick PA. The aftermath ofrRape: Recent empirical findings. American Journal of Orthopsychiatry 1979;49(4):658-69.

2. Rogers C, Gruener D. Sequelae of sexual assault. Primary Care Update for OB/GYN. 1997;4:1430146.

3. Plichta SB, Falik M. Prevalence of violence and its implications for women's health. Women's Health Issues 2001;1 1 (3):244. Epub 11

4. Kaminer D, Grimsrud A, Myer L, Stein DJ, Williams DR. Risk for post-traumatic stress disorder associated with different forms of interpersonal violence in South Africa. Social Science \& Medicine 2008;67:1589-95.

5. Ullman SE, Filipas HH, Townsend SM, Starzynski LL. Psychosocial correlates of PTSD symptom severity in sexual assault survivors. Journal of Traumatic Stress 2007;20(5):821-31.

6. Ullman SE. Social reactions, coping strategies, and self-blame attributions in adjustment to sexual assault. Psychology of Women Quarterly 1996;20(4):505-26.

7. Frese B, Moya M, Megias JL. Social perception of rape: how rape myth acceptance modulates the influence of situational factors. $J$ Interpers Violence 2004;1 9(2):143-61. Epub 2004/03/10.

8. Moore A, Farchi M. Is rape-related self blame distinct from other post traumatic attributions of blame? A comparison of severity and implications for treatment. Women \& Therapy 201 1;34(4):447-60.

9. Ullman SE. Do Social Reactions to Sexual Assault Victims Vary by Support Provider? Violence and Victims 1996; 1 1 (2):143-57.

10. Ullman SE, Filipas HH, Townsend SM, Starzynski LL. The Role of Victim-Offender Relationship in Women's Sexual Assault Experiences. Journal of Interpersonal Violence 2006;21 (6):798819.

11. Temple JR, Weston R, Rodriguez BF, Marshall LL. Differing effects of partner and nonpartner sexual assault on women's mental health. Violence Against Women 2007;13(3):285-97. Epub 2007/02/27.

12. Miller AK, Handley IM, Markman KD, Miller JH. Deconstructing Self-Blame Following Sexual Assault: The Critical Roles of Cognitive Content and Process. Violence Against Women
2010:16(10):1120-37.

13. Ullman SE. Social support and recovery from sexual assault: $A$ review. Aggression and Violent Behavior 1999;4(3):343-58.

14. Jones JS, Wynn BN, Kroeze B, Dunnuck C, Rossman L. Comparison of sexual assaults by strangers versus known assailants in a community-based population. Am J Emerg Med 2004;22 (6):454-9. Epub 2004/11/03.

15. Abrahams N, Jewkes R. Barriers to post exposure prophylaxis (PEP) completion after rape: a South African qualitative study. CultHealth Sex 2010;12(5):471-84.

16. Radloff LS. The CES-D Scale. Applied Psychological Measurement. 1977; 1 (3):385-401

17. Nduna M, Jewkes RK, Dunkle KL, Shai NP, Colman I. Associations between depressive symptoms, sexual behaviour and relationship characteristics: a prospective cohort study of young women and men in the Eastern Cape, South Africa. J Int AIDS Soc 2010;1 3:44. Epub 2010/11/17.

18. Abrahams N, Jewkes R. Barriers to post exposure prophylaxis (PEP) completion after rape: a South African qualitative study. Cult Health Sex 2010;12(5):471-84. Epub 2010102/20.

19. Jewkes R, Dunkle K, Nduna M, Levin J, Jama N, Khuzwayo N, et al. Factors associated with HIV sero-status in young rural South African women: connections between intimate partner violence and HIV. Int J Epidemiol 2006;35(6):1461-8. Epub 2006/09/30.

20. StataCorp 1985-2011 StataCorp LP. Texas: College Station, Texas USA; 2011.

21. Campbell R, Raja S. Secondary Victimization of Rape Victims: Insights From Mental Health Professionals Who Treat Survivors of Violence. Violence and Victims 1999;14(3):261-75.

22. Stein DJ, Seedat S, Herman A, Moomal H, Heeringa SG, Kessler RC, et al. Lifetime prevalence of psychiatric disorders in South Africa. The British Journal of Psychiatry 2008;192(2):112-7.

23. Tomlinson M, Grimsrud AT, Stein DJ, Williams DR, Myer L. The epidemiology of major depression in South Africa: results from the South African stress and health study. S Afr Med J 2009;99(5 Pt 2):367-73. Epub 2009/07/11.

24. Department of Health. South Africa Demographic and Health Survey 1998. Full Report. Pretoria: 2002. http://www.doh.gov.za/docs/reports/2003/sadhs2003/partl.pdf. Date accessed 4 June 2012.

25. Shisana O. Nelson Mandela/HSRC Study of HIVIAIDS: South African National HIV Prevalence, Behavioural Risks and Mass Media Household Survey 2002. Acessed June 2012. http://www.wsu.ac.za/hsrc/html/2007-2.pdf

26. Shisana O, Rehle T, Simbayi L, Parker W, Bhana A, Zuma K, et al. South African National HIV Prevalence, Incidence, Behaviour and Communication Survey Report. Human Sciences Research Council, 2005. http://www.wsu.ac.za/hsrc/html/21 52-9.pdf. Date accessed 12 April 2012

27. Myers B, Louw J, Fakier N. Alcohol and drug abuse: removing structural barriers to treatment for historically disadvantaged communities in Cape Town. International Journal of Social Welfare 2008;17(2):156-65.

28. Campbell R, Dworkin E, Cabral G. An Ecological Model of the Impact of Sexual Assault On Women's Mental Health. Trauma, Violence, \& Abuse 2009;10(3):225-46.

29. Abrahams N, Jewkes R. Managing and resisting stigma: a qualitative study among people living with HIV in South Africa. Journal of the International AIDS Society 2012. Available at: $<$ http://www.jiasociety.org/jias/index.php/jias/article/view/17330>. Date accessed: 31 Aug. 2012 